\title{
Comparison between preoperative and post-operative administration of paracetamol, ibuprofen and mefenamic acid for post-extraction pain control
}

\author{
Govindaraj Padmanabha Kumar ${ }^{1, *}$, Chew Shu-Lyn ${ }^{2}$, Goi Ee Win ${ }^{2}$, Lee Win Sie ${ }^{2}$, \\ Nur Fatin Khaleeda binti Lakman ${ }^{2}$, Nazmul Haque ${ }^{3(0)}$
}

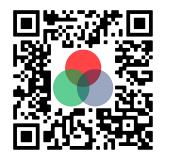

Use your smartphone to scan this QR code and download this article

${ }^{1}$ Department of Oral and Maxillofacial Surgery, Faculty of Dentistry, MAHSA University, Jenjarom, 42610 Selangor, Malaysia

${ }^{2}$ Faculty of Dentistry, MAHSA University, Jenjarom, 42610 Selangor, Malaysia

${ }^{3}$ Department of Oral Biology and Biomedical Sciences, Faculty of Dentistry, MAHSA University, Jenjarom 42610 Selangor, Malaysia

Correspondence

Govindaraj Padmanabha Kumar, Department of Oral and Maxillofacial Surgery, Faculty of Dentistry, MAHSA University, Jenjarom, 42610 Selangor, Malaysia

Email:drgpk1@gmail.com

History

- Received: Feb 20, 2020

- Accepted: May 11, 2020

- Published: May 25, 2020

DOI : 10.15419/bmrat.v7i5.606

\section{Check for updates}

Copyright

(C) Biomedpress. This is an openaccess article distributed under the terms of the Creative Commons Attribution 4.0 International license.

\begin{abstract}
Pain is a common aftereffect following a dental treatment, especially extractions. Hence, the main aim of the study was to compare the effect of pre-operative and post-operative analgesic usage on post-operative pain management following dental treatment. Moreover, the efficacies of three types of painkillers (Paracetamol, Ibuprofen and Mefenamic Acid) in pain relief were also evaluated. Volunteers $(n=120)$ who were undergoing extraction participated in this study and were randomly divided into two groups. One group consisting of 60 participants were given pre- and post-operative analgesics while another group $(n=60)$ received post-operative analgesics only. A visual scale was used to record pain from zero to 56 hours post-operatively at 8-hour intervals. The results showed that patients who were taking analgesics pre-operatively experienced significantly ( $p=0.0045$ ) less pain compared to those who had taken post-operative analgesics only However, a lower cumulative number of moderate and severe experiences of post-extraction pain was recorded for the pre- and post-operative analgesic treatment groups as compared to the postoperative only analgesic treatment group; no significant differences were observed. Moreover, no significant differences were observed among the analgesics used in this study as well. On the basis of these results, we conclude that preoperative analgesic usage has a positive impact on postextraction acute pain management.
\end{abstract}

Key words: Pre-operative pain, Post-operative pain, dental extraction, paracetamol, ibuprofen, mefenamic acid

\section{INTRODUCTION}

Pain increases the anxiety and suffering from patients. However, it helps clinicians to assess the condition, differentiate the causes, diagnose the root cause, and treat the cause at a much earlier stage, thereby preventing more severe problems for the patients ${ }^{1}$. Various methods have been followed to relieve pain either conservatively or post-operatively. Pain relief improves clinic outcomes ${ }^{2}$.

Up to now, several studies have been conducted to ascertain the role of pre- and/or post-operative analgesic usage on the regulation of post-operative oral pain. Hutchinson et al., in their study, showed that use of pre-operative piroxicam (40 mg) reduced doses of paracetamol in the first $24 \mathrm{~h}$ following recovery from anesthesia, while no opioid analgesia was required after surgical removal of lower third molars under general anesthesia ${ }^{3}$. Pre-operative single oral dose of valdecoxib also showed well-tolerated and effective analgesic effects on post-operative bunionectomy pain ${ }^{4}$. In another study, vicoprofen was re- ported as an effective post-operative analgesic medication in the management of acute post-operative dental pain ${ }^{5}$. The effects of pre- and post-operative ibuprofen in preventing post-operative pain has been acknowledged by several researchers ${ }^{6}$.

In the case of other surgeries, such as abdominal and thoracic surgeries, there have also been demonstrated advantages of pre-operatively administered analgesics ${ }^{7}$. However, Nagatsuka et al. did not observe pre-emptive effects from the combination of pre-operative diclofenac, butorphanol and lidocaine in the post-anesthesia care unit ${ }^{8}$. In another study, significant difference in pain control using preoperative naproxen sodium was not observed ${ }^{9}$.

Management of pain in dentistry is challenging for both the patient and the clinician. Pain response results from the inflammatory reactions caused by tissue distortion ${ }^{10}$. Dental procedures involving teeth are generally painless unless it involves the pulp. Disturbance of the adjacent soft tissues and periodontal structures stimulates pain as well. Tooth extraction is one of the common procedure which produces 
inflammation and pain ${ }^{11}$. In dentistry, analgesics are prescribed to relieve acute pain, post-operative pain and chronic pain, and sometimes to control adjunctive intraoperative pain. However, there is no established protocol for its control. Though several studies have been conducted to investigate the efficacy of different types of analgesics administered preoperatively, no study has attempted to analyze the efficacy of different analgesics, namely Paracetamol, Ibuprofen and Mefenamic Acid, in post-extraction pain management. Hence, this study aims to compare the efficacy of analgesics, such as Paracetamol, Ibuprofen and Mefenamic Acid, given pre-operatively and post-operatively in controlling post-extraction pain.

\section{MATERIALS AND METHODS}

\section{Analgesics used}

The following routinely prescribed oral analgesics were used for this study: Paracetamol (500 mg tablet), Ibuprofen (400 mg tablet) and Mefenamic Acid (500 mg tablet). Drugs were administered to patients three times a day (t.i.d).

\section{Inclusion and exclusion criteria}

This study was conducted in the Dental Clinic, Faculty of Dentistry, MAHSA University (Malaysia). The inclusion criteria for selection of the subjects included: adult age (over 18 years of age), patients indicated for extraction under local anesthesia, patients indicated for extraction under local anesthesia with adrenaline of maximum two cartridges, with no other medical complaints, and with no known contraindications for the above-mentioned drugs. On the other hand, pediatric patients, medically-compromised patients, patients with history of active peptic ulcer or ulcerative colitis, and those with history of bronchial asthma with any allergy to the above-mentioned drugs were excluded from the study.

\section{Study design}

Following provision of a signed consent form from each subject, a total of 120 subjects were enrolled in the study. Subjects were randomly divided into two main groups (group A and group B), and each group consisted of three subgroups (A1, A2 and A3, and B1, B2 and B3, respectively). Sixty participants from each group were equally divided into three subgroups $(\mathrm{n}=$ 20). Group A patients received analgesics both preoperatively and post-operatively. Group B patients received drugs post-operatively only. Subgroups 1, 2 and 3 were prescribed Paracetamol, Ibuprofen and Mefenamic Acid, respectively. Visual Analog Scale (VAS) was used to evaluate the patients' postextraction pain until 56 hours at every 8-hour interval (Table 1). Evaluation of pain just after extraction was considered ' 0 ' hour.

\begin{tabular}{cc} 
Table 1: Visual Analog Scale of pain & \\
\hline Pain severity & Scale \\
No Pain & 0 \\
Mild Pain & $1-3$ \\
Moderate Pain & $4-6$ \\
Severe Pain & $7-9$ \\
Worst Pain & 10 \\
\hline
\end{tabular}

\section{Data analysis}

Data were analyzed using Pearson chi-squared $\left(\chi^{2}\right)$ test (SPSS version 22) and the significance level was set at $\mathrm{p}<0.05$.

\section{RESULTS AND DISCUSSION}

Among the patients who received analgesics preoperatively (Group A), 26 reported no post-extraction pain at ' 0 ' hour while only 3 reported severe pain. However, in Group B which received analgesics postoperatively only, 10 patients recorded no pain while 5 developed severe pain (Table 2). Further analysis showed a significant difference $(p=0.0045)$ between pre- and post-operatively treated groups in post-extraction pain control at '0 hour'.

\section{Table 2: Post-extraction pain at '0 hour'}

\begin{tabular}{ccc}
\hline Pain Scale & Group A & Group B \\
0 No Pain & 26 & 10 \\
1-3 Mild Pain & 20 & 20 \\
4-6 Moderate Pain & 11 & 25 \\
7-9 Severe Pain & 3 & 5 \\
10 Worst Pain & 0 & 0 \\
\hline
\end{tabular}

From cumulative and periodical evaluation of postextraction pain until 56 hours, it was observed that the total number of times pain was reported by patients of Group A was lower than that of Group B. Only for 9 times did patients of Group A report severe pain, which was reported 18 times for Group B (Table 3). However, no significant difference $(\mathrm{p}=0.151)$ was observed between pre- and post-operatively treated cohorts with respect to post-extraction pain control out til 56 hours. 
Table 3: Cumulative Post-extraction pain until 56 hours

\begin{tabular}{ccc}
\hline Pain Scale & Group A & Group B \\
0 No Pain & 227 & 216 \\
1-3 Mild Pain & 134 & 122 \\
4-6 Moderate Pain & 51 & 64 \\
7-9 Severe Pain & 9 & 18 \\
10 Worst Pain & 0 & 0 \\
\hline
\end{tabular}

Among the three medications taken in this study to evaluate pain reduction efficiency, patients with severe post-operation pain due to severe inflammatory conditions responded well with Mefenamic Acid, and followed by Ibuprofen; the lowest response was observed for aracetamol administration (Table 4).

Post-operative pain alters or sometimes halts the normal activities of the patient, and increases suffering and anxiety. It disturbs the homeostasis of the endocrine and circulatory systems. Moreover, postoperative pain negatively influences the wound healing process ${ }^{12,13}$. Hence, reliable and fast-onset analgesia is highly needed. This study was designed to test the currently popular belief that pre-operative measures are helpful in the prevention or modification of post-operative pain.

Even though several studies have been done on various aspects of pain management, pain remains the most sensitive and predominant issue from both the doctors' and patients' point of view. Many studies have been conducted on understanding the management of post-operative pain by various means of pre-operative methods, collectively referred to as preemptive analgesia. Prescribing analgesics to patients prior to dental treatment has proven to provide better pain control than post-operatively in many studies. In this study, we have also observed that analgesics used prior to teeth extraction have better effects on postextraction pain control.

Immediately after any surgery, central sensitization induces excitability in the central nervous system ${ }^{14}$. In the head and neck region, inhibition of central sensitization is limited. In contrast, various postsurgical noxious inflammatory stimuli may continuously stimulate local nociceptors and induce peripheral sensitization ${ }^{14}$, which may increase the excitability of dorsal horn neurons and eventually could cause central sensitization ${ }^{15}$. Following establishment of central sensitization, patients respond poorly to analgesics $^{16}$. The surgeries that are linked to the strong post-surgical inflammatory reactions usually cause sensitized severe post-operative pain. Hence, the concept of pre-emptive analgesia is introduced to prevent central sensitization before surgery to help minimize post-operative pain ${ }^{17}$.

Several randomized control studies have shown the post-operative pain inhibitory potential of pre-operative non-steroidal anti-inflammatory drugs (NSAIDs) in tooth removal. In this study, we have also observed significantly less experience of acute pain following extraction in those patients who took analgesics pre-operatively. This could be because of the inhibition of central sensitization that results from tissue damage during removal of the impacted tooth and the inhibition of peripheral sensitization that results from inflammation following tooth removal. In this study, only a few patients developed severe pain in the pre-operative group which could be due to secondary infections in patients not following the instructions or maintaining poor oral hygiene.

\section{CONCLUSIONS}

Post-operative pain is a common complication following extraction. In our study, patients prescribed with analgesics prior to dental treatment reportedly experienced lower pain level post-treatment as compared to patients prescribed only post-operatively. The types of analgesics in our study, namely Paracetamol, Ibuprofen and Mefenamic Acid, affect the postoperative pain differently. Though there were no significant differences in efficacy among the analgesics used in this study, Ibuprofen and Mefenamic Acid showed better anti-inflammatory properties compared to Paracetamol and, thus, in reducing pain levels post-operatively as well.

On the basis of the results of this study, we can conclude that in dental extraction cases, use of preoperative analgesics may help to attenuate central sensitization while post-operative peripheral sensitization could be inhibited by administering postoperative analgesics. Moreover, this preventive analgesia method could be most effective method in controlling post-operative pain in other dental surgeries as well. Hence, for dental extractions and minor oral surgical procedures, analgesics should be given preoperatively to mitigate post-operative pain and to reduce post-operative pain medication dosage requirement, thereby supporting a better healing process.

\section{ABBREVIATIONS}

COX: Cyclooxygenase

CNS: Central Nervous System

H0: Null hypotheses

H1: Alternative hypotheses 
Table 4: Comparison among the analgesics in maintain post-extraction pain at '0 hour'

\begin{tabular}{|c|c|c|c|c|c|c|}
\hline \multirow[t]{2}{*}{ Scale } & \multicolumn{3}{|c|}{ Group A } & \multicolumn{3}{|c|}{ Group B } \\
\hline & A1 & A2 & A3 & B1 & B2 & B3 \\
\hline 0 No Pain & 9 & 8 & 9 & 3 & 4 & 3 \\
\hline 1-3 Mild Pain & 6 & 7 & 7 & 6 & 7 & 7 \\
\hline 4-6 Moderate Pain & 4 & 3 & 4 & 10 & 7 & 8 \\
\hline 7-9 Severe Pain & 1 & 2 & 0 & 1 & 2 & 2 \\
\hline 10 Worst Pain & 0 & 0 & 0 & 0 & 0 & 0 \\
\hline
\end{tabular}

NSAIDs: Non-steroidal anti- inflammatory drugs

PCM: Paracetamol

Post-op: Post-operative

Pre-op: Pre-operative

t.i.d.: ter in die, three times daily

\section{ACKNOWLEDGMENTS}

The authors would like to thank the Staff Nurses from Oral and Maxillofacial Surgery Department, supporting staffs from dental clinic and all year 5 students of 2017-2018 batch, Faculty of Dentistry, MAHSA University; and all supporting staffs from MAHSA Dental Clinic, Jalan Dang Wangi for their support in this study.

\section{AUTHOR'S CONTRIBUTIONS}

GPK conceptualized and designed the work. CSL, GEW, LWS and NFKL carried out the experiment. GPK and NH conducted formal analysis. GPK, CSL, GEW, LWS, NFKL and NH prepared the original draft. GPK and NH reviewed and edited the drafts. All authors read and approved the final manuscript.

\section{FUNDING}

Not applicable.

\section{AVAILABILITY OF DATA AND MATERIALS}

The basic clinical data used to support the findings of this study are included within the article. The data used to support the findings of this study are restricted in order to protect patients privacy, but available from the corresponding author upon request. (To contact Dr. G. Padmanabha Kumardrgpk1@gmail.com)

\section{ETHICS APPROVAL AND CONSENT TO PARTICIPATE}

This study was conducted in accordance with the amended Declaration of Helsinki. The institutional review board approved the study, and all participants provided written informed consent.

\section{CONSENT FOR PUBLICATION}

Not applicable.

\section{COMPETING INTERESTS}

The authors declare that they have no competing interests.

\section{REFERENCES}

1. Häuser W, Perrot S, Sommer C, Shir Y, Fitzcharles MA. Diagnostic confounders of chronic widespread pain: not always fibromyalgia. Pain reports. 2017;2(3):e598-e. PMID: 29392213. Available from: https://doi.org/10.1097/PR9. 0000000000000598.

2. Galicia-Castillo M. Opioids for persistent pain in older adults. Cleve Clin J Med. 2016;83(6):443-451. PMID: 27281257. Available from: https://doi.org/10.3949/ccjm.83a.15023.

3. Hutchison GL, Crofts SL, Gray IG. Preoperative piroxicam for postoperative analgesia in dental surgery. $\mathrm{Br} \mathrm{J}$ Anaesth. 1990;65(4):500-503. PMID: 2248816. Available from: https: //doi.org/10.1093/bja/65.4.500.

4. Desjardins PJ, Shu VS, Recker DP, Verburg KM, Woolf CJ. A single preoperative oral dose of valdecoxib, a new cyclooxygenase-2 specific inhibitor, relieves post-oral surgery or bunionectomy pain. Anesthesiology. 2002;97(3):565-573. PMID: 12218521. Available from: https://doi.org/10.1097/ 00000542-200209000-00008.

5. Ziccardi VB, Desjardins PJ, Daly-DeJoy E, Seng GF. Single-dose vicoprofen compared with acetaminophen with codeine and placebo in patients with acute postoperative pain after third molar extractions. J Oral Maxillofac Surg. 2000;58(6):622-628. Available from: https://doi.org/10.1016/S0278-2391(00)90154$\mathrm{X}$.

6. Pozzi A, Gallelli L. Pain management for dentists: the role of ibuprofen. Annali di stomatologia. 2011;2(3-4 Suppl):3-24.

7. Dahl JB, Møiniche S. Pre-emptive analgesia. Br Med Bull. 2004;71(1):13-27. PMID: 15596866. Available from: https: //doi.org/10.1093/bmb/ldh030.

8. Nagatsuka C, Ichinohe T, Kaneko Y. Preemptive effects of a combination of preoperative diclofenac, butorphanol, and lidocaine on postoperative pain management following orthognathic surgery. Anesth Prog. 2000;47(4):119-124.

9. Sisk AL, Grover BJ. A comparison of preoperative and postoperative naproxen sodium for suppression of postoperative pain. J Oral Maxillofac Surg. 1990;48(7):674-678. Available from: https://doi.org/10.1016/0278-2391(90)90048-7.

10. Chen L, Deng H, Cui H, Fang J, Zuo Z, Deng J, et al. Inflammatory responses and inflammation-associated diseases in organs. Oncotarget. 2017;9(6):7204-7218. PMID: 29467962. Available from: https://doi.org/10.18632/oncotarget.23208. 
11. Renton T. Dental (Odontogenic) Pain. Reviews in pain. 2011;5(1):2-7. PMID: 26527224. Available from: https://doi. org/10.1177/204946371100500102.

12. Chapman CR, Tuckett RP, Song CW. Pain and stress in a systems perspective: reciprocal neural, endocrine, and immune interactions. The journal of pain : official journal of the American Pain Society. 2008;9(2):122-145. PMID: 18088561. Available from: https://doi.org/10.1016/j.jpain.2007.09.006.

13. Pogatzki-Zahn EM, Segelcke D, Schug SA. Postoperative painfrom mechanisms to treatment. Pain reports. 2017;2(2):e588e. PMID: 29392204. Available from: https://doi.org/10.1097/ PR9.0000000000000588.

14. Latremoliere A, Woolf CJ. Central sensitization: a generator of pain hypersensitivity by central neural plasticity. The journal of pain : official journal of the American Pain Society. 2009;10(9):895-926. PMID: 19712899. Available from: https://doi.org/10.1016/j.jpain.2009.06.012.
15. Yamaguchi A, Sano K. Effectiveness of preemptive analgesia on postoperative pain following third molar surgery: Review of literatures. Japanese Dental Science Review. 2013;49(4):131-138. Available from: https://doi.org/10.1016/ j.jdsr.2013.07.002.

16. Woolf CJ, Chong MS. Preemptive analgesia-treating postoperative pain by preventing the establishment of central sensitization. Anesth Analg. 1993;77(2):362-379. PMID: 8346839 Available from: https://doi.org/10.1213/00000539-19937702000026.

17. Hurley RW, Enneking FK. Chapter 27 - Preemptive and preventive analgesia. In: Benzon HT, Raja SN, Liu SS, Fishman SM, Cohen SP, Hurley RW, et al., editors. Essentials of Pain Medicine (Third Edition). Saint Louis: WB Saunders. 2011;p. 200-205. Available from: https://doi.org/10.1016/B978-1-4377-2242-0. 00036-5. 